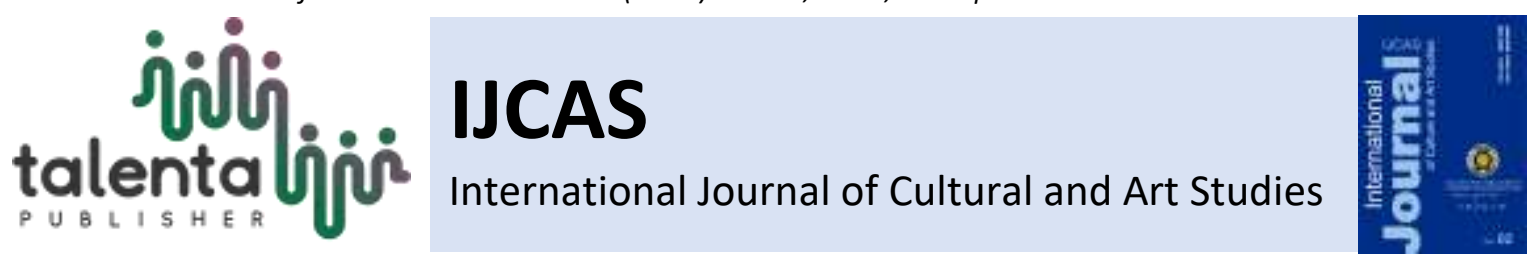

\title{
The Devoicing Intensity of Vowels [I] and [U]] in Japanese Language
}

\author{
Siti Muharami Malayu ${ }^{1 *}$, Yuddi Adrian Muliadi ${ }^{2}$ \\ ${ }^{1,2}$ Departmen of Japanese Literature, University of Sumatera Utara, Medan, Indonesia
}

\begin{abstract}
The research analyzed the intensity of devoicing vowels [i] and [u] in Japanese language by its learners. The research used theory of Accoustic Phonetics with Praat Program to measure the intensity of vowels [i] and [u]. It analyzed 6 target words uttered by two Japanese Language Learners. A native Japanese speaker was used as the utterance model. It began with recording the voice of the learners in Medan. The research problem was how the intensity of the devoicing of vowels [i] and [u] in the first syllable uttered by Japanese Language learners in Medan. The findings, based on Praat analysis with intensity measurement, showed that the intensity of the devoicing of vowels [i] and [u] in the first syllable uttered by the four Japanese Language learners was not maximal.
\end{abstract}

Keywords: Intensity of vowel, Japanese, Japanese Language Learners.

Received 24 February 2019| Revised 15 April 2019| Accepted 23 April 2019

\section{Introduction}

If one wants to know his country well, he should understand its language and culture. Japanese language is not the first or mother-tongue language for Indonesians. Foreign language learning often makes mistakes due to the influence of mother tongue or local dialects. Such mistakes can be found in all aspects of grammar either in phonology, morphology, syntax, or semantics. As the results, misunderstanding is frequently found in communication that hinders the intended message to be understood.

Japanese consists of four skills (yonginou) which are well arranged, beginning from birth i.e. 'listening', then 'speaking', 'reading,' and finally 'writing'. These skills can be classified into two groups; namely, speaking and listening are the productive or active skills while listening and reading are the comprehending or passive skills.

\footnotetext{
*Corresponding author at: Department of Japanese Literature, Faculty of Cultural Studies, Universitas Sumatera Utara, Jalan Universitas No. 19, Medan 20155, Indonesia

E-mail address: sitimuharamimalayu@yahoo.com
} 
Phonologically, Japanese syllables are mostly open syllables; they are ended by particular vowels unless there is additional nasal sound (hatsuon) and double consonants (sokuon) on the syllables.

There are three things required to produce language sound; namely, airflow, articulator, and articulation point. Communication which takes place in the production process starts either in oral or nasal cavity, and then it proceeds to the ears and is received by the interlocutor's ears so that the sound can be understood. These three events differentiated in Phonetics into articulatoric phonetics (chou-on onseigaku), acoustic phonetics (onkyou onseigaku), and auditorial phonetics (choukaku onseigaku).

Viewed from the phonetic aspect, devoicing can be analyzed acoustically so that the intensity can be observed, depending on the characters of the Japanese utterances. According to phonetic studies, language sound analysis which particularly focuses on a certain language to reveal its sound system is known as phonological study.

In Japanese there is a term, boin no museika. According to Kimura[1], Dahidi and Michie translated it into 'vowel devoicing' and Tsujimura[2] 'calls it devoicing vowels'. What is meant by 'vowel devoicing' is that the change from voiced to voiceless, so that the vowel quality becomes less. The high quality of vowels [i] and [u] is decreased in a particular phonemic circumstance; namely, when there are voiceless consonants. It can be observed that when Japanese people speak, some phonems such as [i] and [u] are not frequently uttered fully voiceless. For example, when they pronounce the work takusan 'many', hito 'people/nation', shita 'under', vowels [i] and [u] which are in the middle of the words takusan, hito, shita, are not fully voiceless. The words arigatoo gozaimasu 'thank you', which is ended with vowel [u], is not pronounced fully voiceless. The same case applies when the word ikimasu 'go' is pronounced; it is heard as if they say kimasu 'come', because the vowel [i] in the beginning is not fully voiceless. According to Tanaka and Kubuzono [3], in Japannese pronunciation, this devoicing of vowel cannot be ignored. These vowels should be truly pronounced voiceless so that Japanese language learners can speak well and fluently like a native speaker.

According to some previously conducted researches, there has not been any research that identifies the intensity of devoicing vowel in Japanese. Intensity can be measured by means of computer program such as CRSE (Computerized Research Speech Environment and Praat. These programs can measure sound intensity uttered by informants.

The problem analyzed is the intensity of vowels [i] and [u] in the first syllable uttered by four Japanese language learners and a native speaker uttering 6 words.

The research results are expected to be useful for Japanese Language learning, particularly in its pronunciation. 


\section{Theoretical Framework}

The research focused on the intensity of the devoicing vowels [i] and [u] in first syllable. There is a term in Japanese, 日本語の母音の無声化 Ni hongo no boin no muuseika (devoicing vowels in Japanese). Devoicing vowels in Japanese is pronouncing vowel sounds voiceless, so that the quality of the vowel sound lessened. The sound quality of phonemes [i] and [u] is lessened when they are found in certain circumstances; such as in voiceless consonants. Kimura [1] states that (1) vowels [i] and [u] are devoiced when they are between voiceless consonants; (2) when unaccented consonants in the end of the word are voiceless, so that vowels [i] and [u] are devoiced. Therefore, in this research the term, boin no museika can refer to 'devoicing vowels'.

The different characteristics of vowel [i] in Japanese is that it is in the front, high and not round; while vowel [u] is in the back, high and not round. According to Tsujimura [2], this devoicing most frequently takes place on high vowels, /i/ and /w/.

Ladefoged [4] states that the quality of a sound, including vowel sound, depends on the structure of additional tone. It can be said that a vowel sound consists of a number of different tones simultaneously. There is a tone when the sound is truly uttered and there are additional tones giving different features on the sound. A vowel sound can be differentiated from the other vowel sounds by these additional tones.

Intensity is related to the loudness-softness of a sound. The acoustic characteristics of intensity are measured in decibel $(\mathrm{dB})$. In sound signal, utterance intensity is represented in the amplitude of a sound wave. The bigger the amplitude is, the higher the intensity of the sound. Vowels generally have bigger amplitude compared with consonants. [5]

According to Ladfoged[6], the loudness-softness level of sounds can be determined by connecting it with its acoustic couple; namely, the intensity which is the measurement for the acoustic energy. The loudness-softness (also called intensity) is sometimes considered as a stress (tense) marker. Different utterances have different intensity, even when uttered at the same stress level. Moreover, voiced sounds have higher intensity than the devoiced ones. For vowel sounds, the intensity is usually proportional with the openness level of mouth.

Ladefoged [4] states that intensity is also called amplitude of variations in air pressure. In every utterance, the intensity of each segment depends on many factors such as the position in a sentence, stress level of each word, and speaker's personal characters.

Japanese is well-known as a language which is rich of letters, yet lacks of sounds. It consists of five vowels, and some consonants that are followed by the vowels to form an open syllable. There are only five vowels in Japanese; namely, /a/, /i/, /u/, /e/, and /o/. Vowels are formed due 
to the air flowed from lungs that vibrates the vocal cords. Vowels are mainly determined by tongue position; whether it goes up or down, and whether it is the front, middle, or back side. Vowels in Japanese are also determined by the round or not the lips to pronounce them.

\section{Research Method}

The research used qualitative descriptive method to obtain a more detailed description of the intensity of devoicing vowels [i] and [u] in the first syllables of the words uttered by Japanese language learners. A Japanese native speaker was made as the utterance model. The uttered sounds were processed by helping device/ instruments so that the intensity can be visualzed and used as the ground for further measurements.

The utterance recorded from one Japnese native speaker was named PA. The four Japanese language learners in Medan consisted of 2 persons from Japanese Literature Study Program of the Faculty of Cultural Science at the University of Sumatera Utara (henceforth they were called PU) and 2 persons from Japanese Language Department of STBA (Higher Education for Foreign Language) Harapan Medan (hereforth they were called PH). The recorded utterance data were analyzed by means of measurement instrument, Praat program, in accordance with IPO (Institut voor Perceptie Onderzoek) approach; an approach designed to describe acoustic signals. The results of the utterance melodic curve were used to measure the intensity. The qualitative approach was used to make a systematic and accurate description of the facts and correlations among the studied phenomenon.

The data used in the research was utterance in Japanese. The data consisted of 6 target words; namely, [iki] 'breath', [ufi] 'cow', [ikiru] 'alive', [ussuru] 'reflected', [ikimasu] 'go', and [utfikefi] 'cancellation' which emphasized on the devocing vowels [i] and [u]. The six target words used as the data in this research had devoicing vowels [i] and [u] in the first syllables.

The data were recordings of utterance obtained from a recorder. The next step was data classification. It was conducted to facilitate the process of qualitative analysis. There were some steps in data classification; namely, the recording of the uttered six target words, by the Japanese native speaker and language learners. The next step was digitalization, and then data segmentation using Praat program to obtain the data for the intensity measurement of the target words.

The analysis steps in the research were firstly, digitalization, transferring the manual recorded data into digital form by means of Praat program application; namely in WAV (Wave Sound Format); secondly, data segmentation, sorting out sound per sound of the digitalized utterances; thirdly, by means of Praat program application were obtained the acoustic signals of the uttered sounds which were series of uttered sound waves; and fourth, the production of tone flow copy. 
This production was used to obtain the intensity of continuum data $(\mathrm{dB})$ of an utterance, either the first intensity, last intensity, high and low intensity, or comprehensive intensity contour identification.

\section{Research Results}

Differences in the measurement of inter-syllable intensity in an utterance due to devoicing process are indicated to be found in Japanese. Intensity determination, based on the loud and clear of sound acoustically, is rooted in the broad and wide ranging of air waves. The sound per syllable also has a comprehensive intensity on vowels. In this research, a syllable forming an utterance is also measured for its intensity using decibel $(\mathrm{dB})$ unit. It mainly occurs on vowels [i] and [u]. Therefore, it is necessary to conduct a research on the measurement and comparison of the syllable intensity. The devoiced syllable has relatively low intensity compared with the one which is not devoiced.

The research on intensity here refers to the intensity of vowels [i] and [u] in the target words. The analysis was measured from word aspect. The devoicing process was observed from the position of vowels [i] and [u] in a word, either it is in the first, middle, or last. In this research in particular, the analysis merely focused on the vowel position in the first syllable of the words.

The devoicing intensity of vowels [i] for the word [iki] by the Japanese native speaker is illustrated in the following figure.

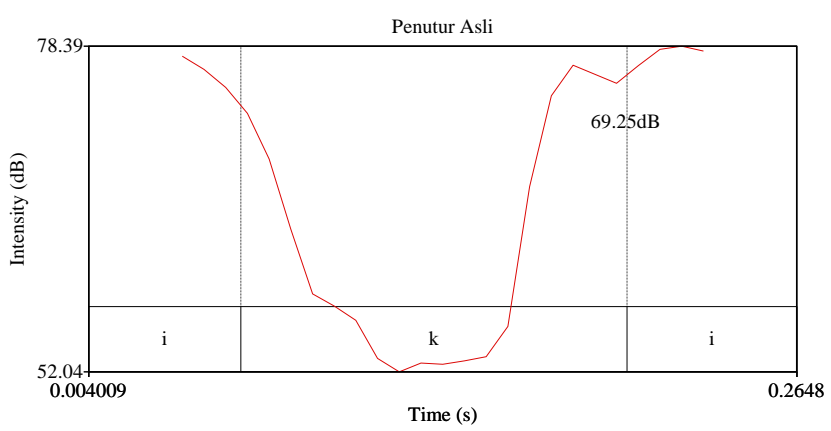

Figure 1. Intensity of a native speaker for the word $i k i$

The devoicing of vowel [i] in the first syllable of the word [iki] uttered by the Japanese native speaker shows basic intensity $69.26 \mathrm{~dB}$, minimum intensity $52.04 \mathrm{~dB}$, and maximum intensity $78.39 \mathrm{~dB}$.

Meanwhile, the devoicing intensity of vowel [i] uttered by the Japanese language learners from USU (PU-1) for the word [iki] is demonstrated by the following figure. 


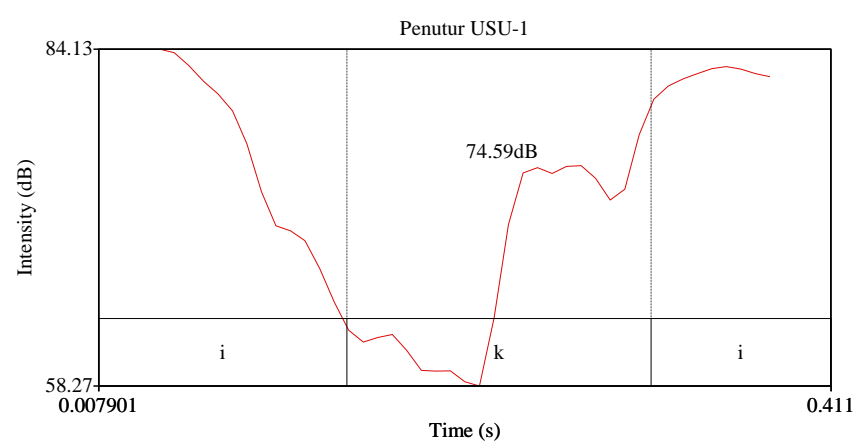

Figure 2. Intensity of USU-1 speaker for the word $i k i$

The devoicing of vowel [i] in the first syllable of the word [iki] uttered by the PU-1 speaker shows basic intensity $74.59 \mathrm{~dB}$, minimum intensity $58.27 \mathrm{~dB}$, and maximum intensity $84.13 \mathrm{~dB}$.

The devoicing intensity of vowel [i] for the word [iki] by the Japanese language learners from USU (PU-2) is showed by the following figure.

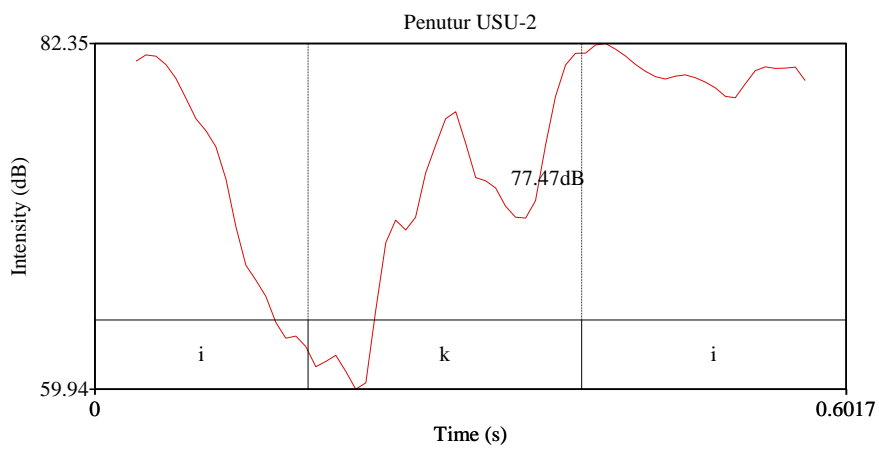

Figure 3. Intensity of USU-2 speaker for the word $i k i$

The devoicing of vowel [i] in the first syllable of the word [iki] uttered by the PU-2 speaker shows basic intensity $77.47 \mathrm{~dB}$, minimum intensity $59.94 \mathrm{~dB}$, and maximum intensity $82.35 \mathrm{~dB}$.

The devoicing intensity of vowel [i] for the word [iki] by the Japanese language learners from STBA Harapan (PH-1) is showed by the following figure.

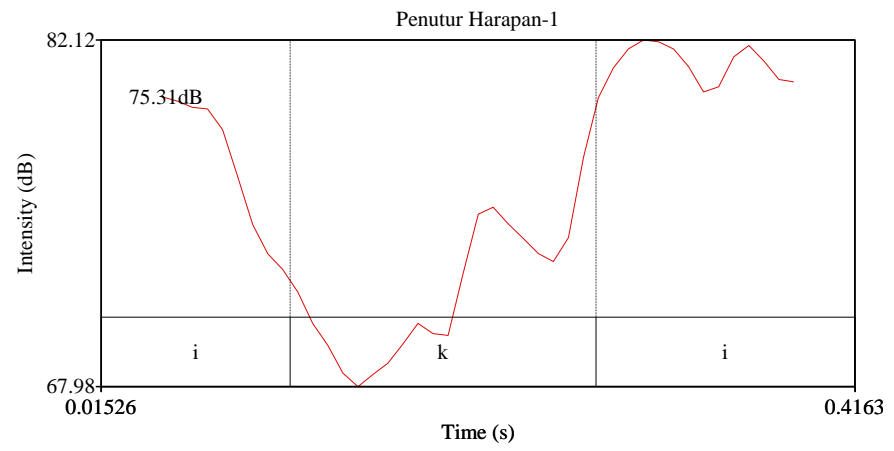

Figure 4. Intensity of Harapan-1 speaker for the word [iki] 
The devoicing of vowel [i] in the first syllable of the word [iki] uttered by the PH-1 speaker shows basic intensity $75.31 \mathrm{~dB}$, minimum intensity $67.98 \mathrm{~dB}$, and maximum intensity $82.12 \mathrm{~dB}$.

The devoicing intensity of vowel [i] for the word [iki] by the Japanese language learners from STBA Harapan (PH-2) is showed by the following figure.

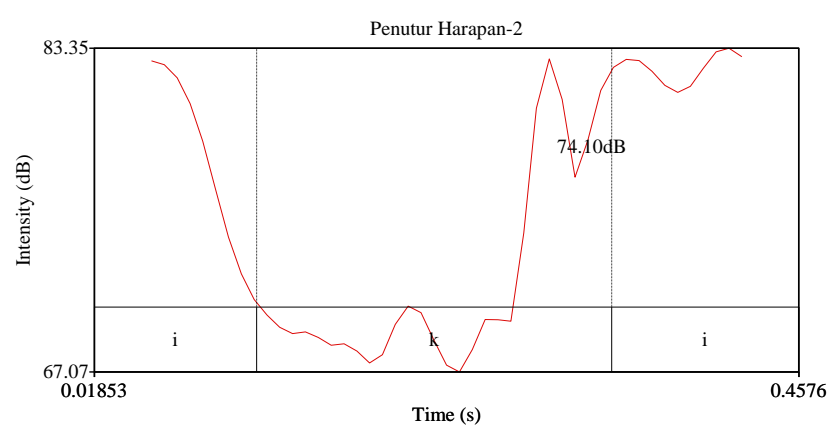

Figure 5. Intensity of Harapan-2 speaker for the word $i k i$

The devoicing of vowel [i] in the first syllable of the word [iki] uttered by the PH-2 speaker shows basic intensity $74.10 \mathrm{~dB}$, minimum intensity $67.07 \mathrm{~dB}$, and maximum intensity $83.35 \mathrm{~dB}$.

The devoicing intensity of vowel $[u]$ for the word $[u / i]$ by the Japanese native speaker is illustrated in the following figure.

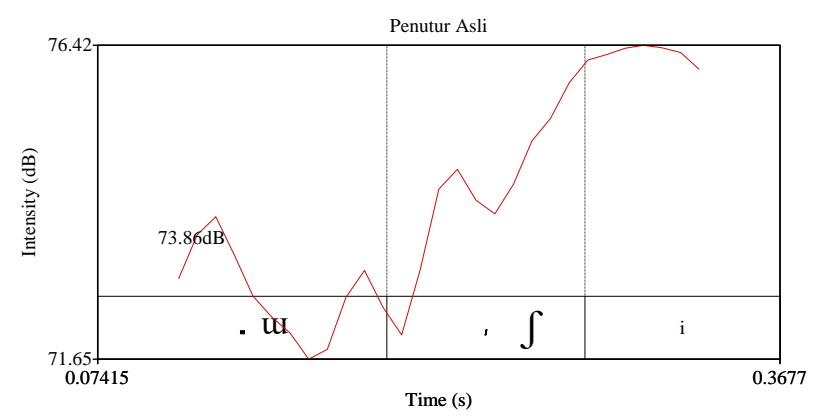

Figure 6. Intensity of a native speaker for the word $u / i$

The devoicing of vowel $[\mathrm{w}]$ in the first syllable of the word $[\mathrm{m} / \mathrm{i}]$ uttered by the Japanese native speaker shows basic intensity $73.86 \mathrm{~dB}$, minimum intensity $71.65 \mathrm{~dB}$, and maximum intensity $76.42 \mathrm{~dB}$.

The devoicing intensity of vowel $[u]$ in the first syllable of the word $[u f i]$ uttered by the Japanese language learners from USU (PU-1) is demonstrated by the following figure. 


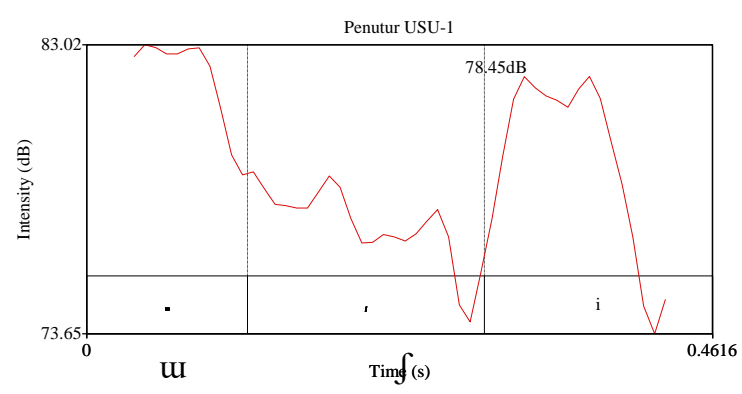

Figure 7. Intensity of USU-1 speaker for the word $m / i$

The devoicing of vowel [u] in the first syllable of the word $[u / i]$ uttered by the PU-1 speaker shows basic intensity $78.45 \mathrm{~dB}$, minimum intensity $73.65 \mathrm{~dB}$, and maximum intensity $83.02 \mathrm{~dB}$.

The devoicing intensity of vowel $[u]$ in the first syllable of the word $[u / i]$ by the Japanese language learners from USU (PU-2) is showed by the following figure.

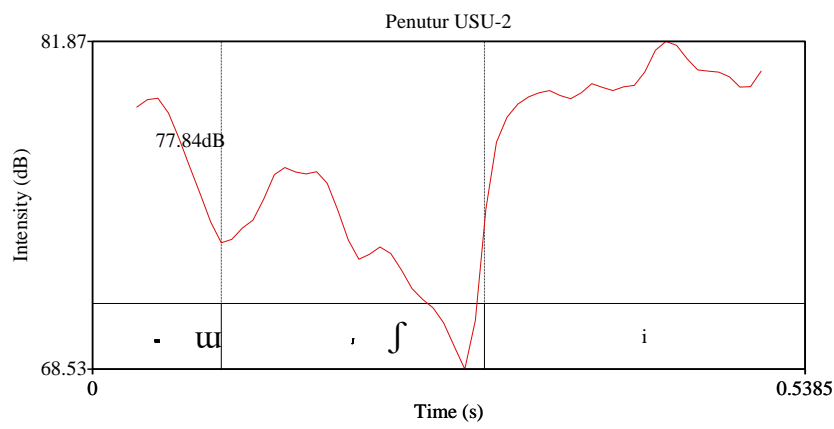

Figure 8. Intensity of USU-2 speaker for the word $m / i$

The devoicing of vowel $[\mathrm{w}]$ in the first syllable of the word $[u / i]$ uttered by the PU-2 speaker shows basic intensity $77.84 \mathrm{~dB}$, minimum intensity $68.53 \mathrm{~dB}$, and maximum intensity $81.87 \mathrm{~dB}$.

The devoicing intensity of vowel $[\mathrm{w}]$ in the first syllable of the word $[\mathrm{w} / \mathrm{i}]$ by the Japanese language learners from STBA Harapan (PH-1) is showed by the following figure.

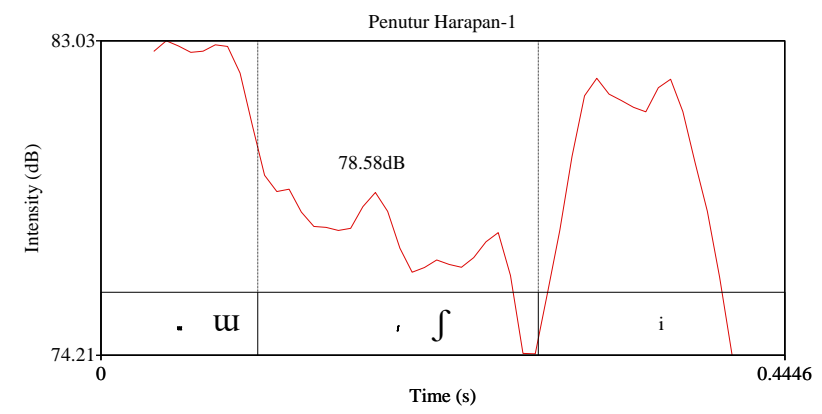

Figure 9. Intensity of Harapan-1 speaker for the word $m / i$

The devoicing of vowel $[\mathrm{w}]$ in the first syllable of the word $[u / i]$ uttered by the PH-1 speaker shows basic intensity $78.58 \mathrm{~dB}$, minimum intensity $74.21 \mathrm{~dB}$, and maximum intensity $83.03 \mathrm{~dB}$. 
The devoicing intensity of vowel $[\mathrm{w}]$ in the first syllable of the word $[u / i]$ by the Japanese language learners from STBA Harapan (PH-2) is showed by the following figure.

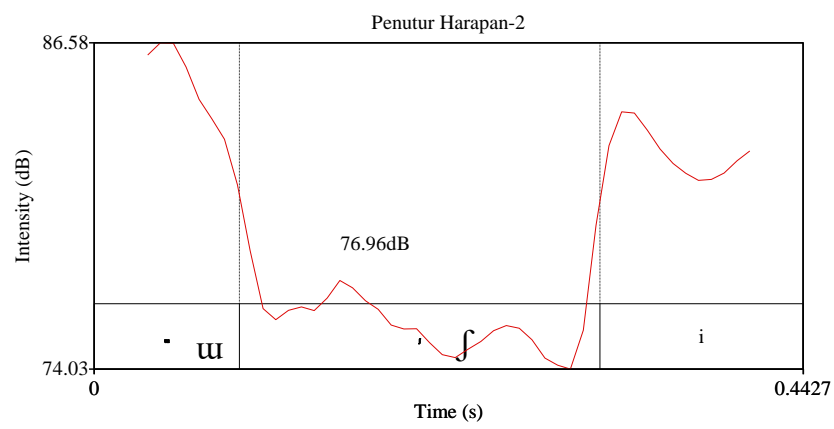

Figure 10. Intensity of Harapan-2 speaker for the word $u / i$

The devoicing of vowel [u] in the first syllable of the word $[u / i]$ uttered by the PH-2 speaker shows basic intensity $76.96 \mathrm{~dB}$, minimum intensity $74.03 \mathrm{~dB}$, and maximum intensity $86.58 \mathrm{~dB}$.

The devoicing intensity of vowel [i] in the first syllable of the word [ikiru] by the Japanese native speaker is illustrated in the following figure.

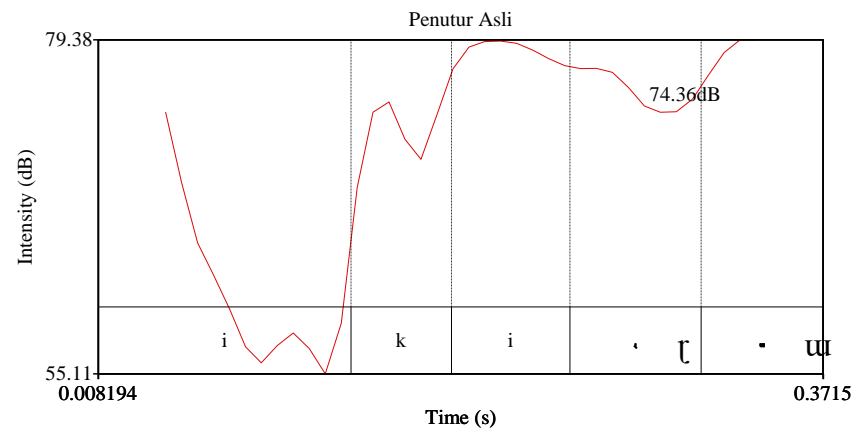

Figure 11. Intensity of a native speaker for the word ikirm

The devoicing of vowel [i] in the first syllable of the word [ikiru] uttered by the Japanese native speaker shows basic intensity $74.36 \mathrm{~dB}$, minimum intensity $55.11 \mathrm{~dB}$, and maximum intensity $79.38 \mathrm{~dB}$.

The devoicing intensity of vowel [i] in the first syllable of the word [ikirm] uttered by the Japanese language learners from USU (PU-1) is demonstrated by the following figure. 


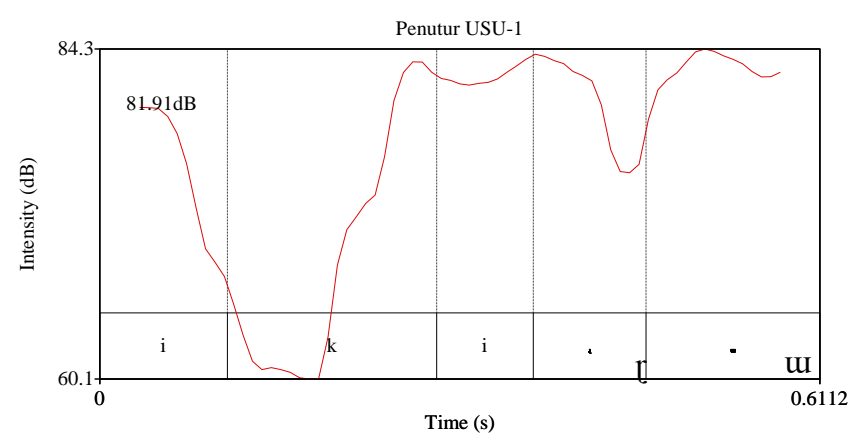

Figure 12. Intensity of USU-1 speaker for the word ikirm

The devoicing of vowel [i] in the first syllable of the word [ikiru] uttered by the PU-1 speaker shows basic intensity $81.91 \mathrm{~dB}$, minimum intensity $60.1 \mathrm{~dB}$, and maximum intensity $84.3 \mathrm{~dB}$.

The devoicing intensity of vowel [i] in the first syllable of the word [ikirm] by the Japanese language learners from USU (PU-2) is showed by the following figure.

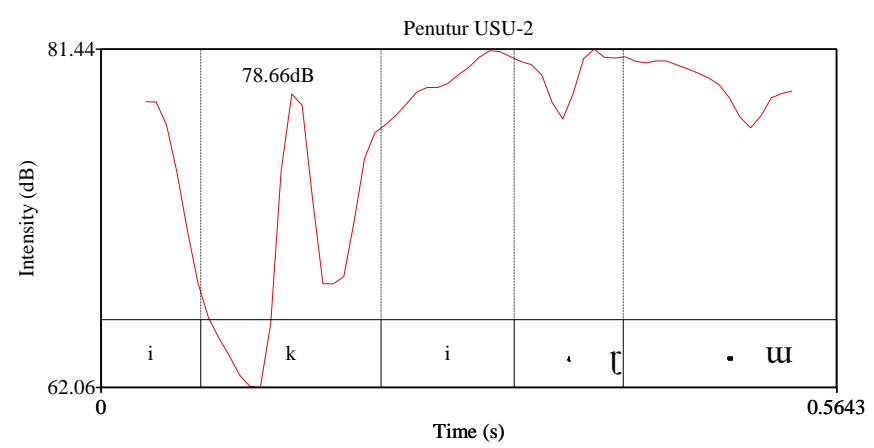

Figure 13. Intensity of USU-2 speaker for the word ikirm

The devoicing of vowel [i] in the first syllable of the word [ikiru] uttered by the PU-2 speaker shows basic intensity $78.66 \mathrm{~dB}$, minimum intensity $62.06 \mathrm{~dB}$, and maximum intensity $81.44 \mathrm{~dB}$.

The devoicing intensity of vowel [i] in the first syllable of the word [ikiru] by the Japanese language learners from STBA Harapan (PH-1) is showed by the following figure.

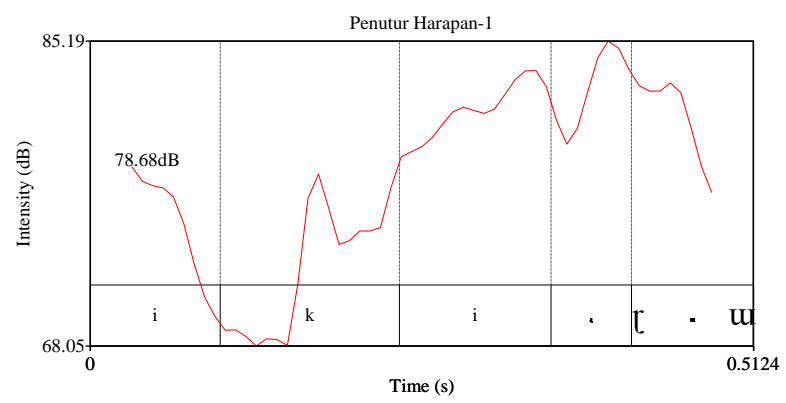

Figure 14. Intensity of Harapan-1 speaker for the word ikiru 
The devoicing of vowel [i] in the first syllable of the word [ikirm] uttered by the PH-1 speaker shows basic intensity $78.68 \mathrm{~dB}$, minimum intensity $68.05 \mathrm{~dB}$, and maximum intensity $76.94 \mathrm{~dB}$.

The devoicing intensity of vowel [i] in the first syllable of the word [ikiru] by the Japanese language learners from STBA Harapan ( $\mathrm{PH}-2)$ is showed by the following figure.

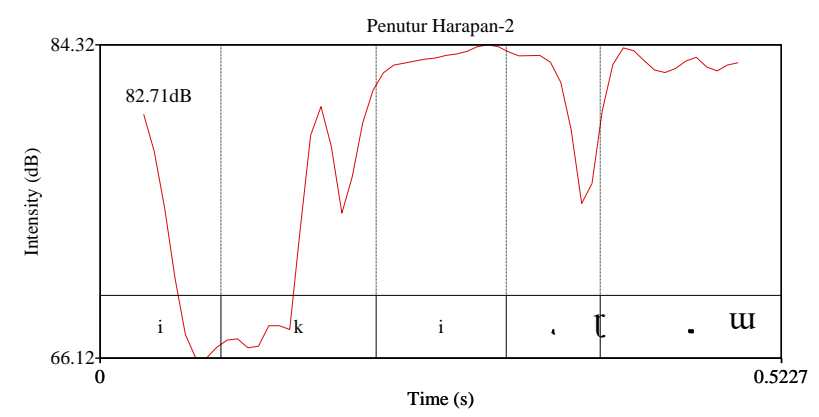

Figure 15. Intensity of Harapan-2 speaker for the word ikiru

The devoicing of vowel [i] in the first syllable of the word [ikiru] uttered by the PH-2 speaker shows basic intensity $82.71 \mathrm{~dB}$, minimum intensity $66.12 \mathrm{~dB}$, and maximum intensity $84.32 \mathrm{~dB}$.

The devoicing intensity of vowel $[\mathrm{u}]$ in the first syllable of the word [utsuru] by the Japanese native speaker is illustrated in the following figure.

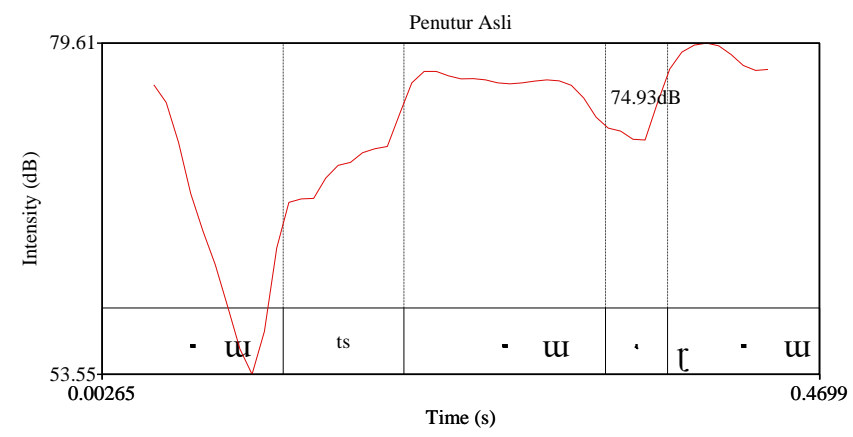

Figure 16. Intensity of a native speaker for the word utsmrm

The devoicing of vowel [u] in the first syllable of the word [utsuru] uttered by the Japanese native speaker shows basic intensity $74.93 \mathrm{~dB}$, minimum intensity $53.55 \mathrm{~dB}$, and maximum intensity $79.61 \mathrm{~dB}$.

The devoicing intensity of vowel [u] in the first syllable of the word [utsuru] uttered by the Japanese language learners from USU (PU-1) is demonstrated by the following figure. 


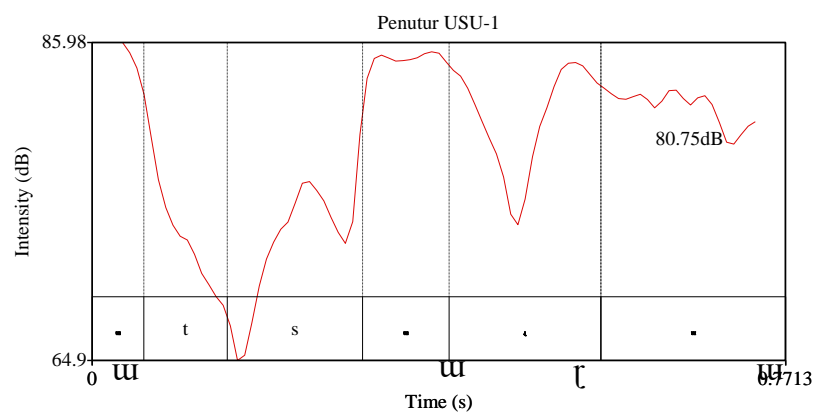

Figure 17. Intensity of USU-1 speaker for the word utsmru

The devoicing of vowel [u] in the first syllable of the word [utsurm] uttered by the PU-1 speaker shows basic intensity $80.75 \mathrm{~dB}$, minimum intensity $64.9 \mathrm{~dB}$, and maximum intensity $85.98 \mathrm{~dB}$.

The devoicing intensity of vowel $[w]$ in the first syllable of the word [utsuru] by the Japanese language learners from USU (PU-2) is showed by the following figure.

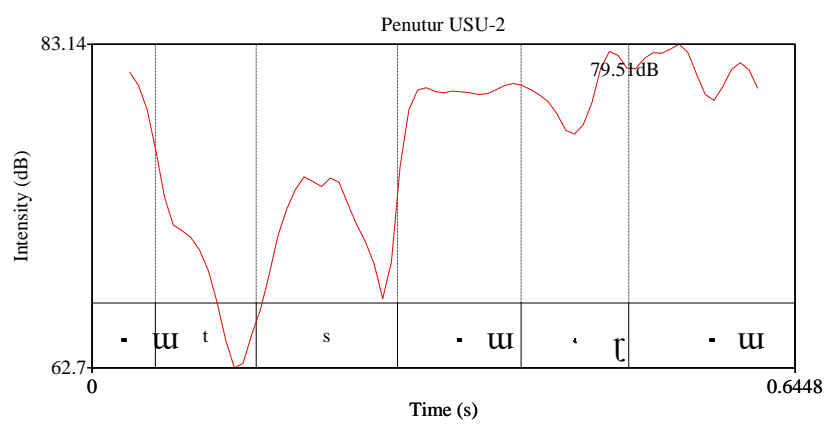

Figure 18. Intensity of USU-2 speaker for the word utsuru

The devoicing of vowel [u] in the first syllable of the word [uswru] uttered by the PU-2 speaker shows basic intensity $79.51 \mathrm{~dB}$, minimum intensity $62.7 \mathrm{~dB}$, and maximum intensity $83.14 \mathrm{~dB}$.

The devoicing intensity of vowel [u] in the first syllable of the word [utsuru] by the Japanese language learners from STBA Harapan (PH-1) is showed by the following figure.

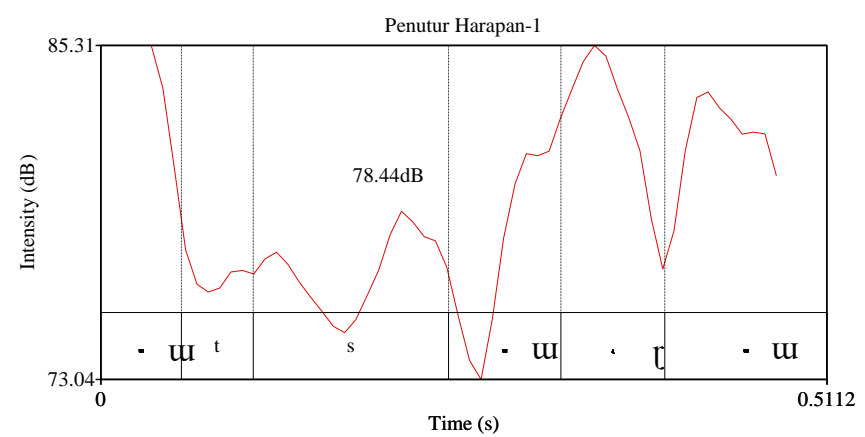

Figure 19. Intensity of Harapan-1 speaker for the word utsuru 
The devoicing of vowel [u] in the first syllable of the word [utsuru] uttered by the PH-1 speaker shows basic intensity $78.44 \mathrm{~dB}$, minimum intensity $73.04 \mathrm{~dB}$, and maximum intensity $85.31 \mathrm{~dB}$.

The devoicing intensity of vowel [u] in the first syllable of the word [utsuru] by the Japanese language learners from STBA Harapan (PH-2) is showed by the following figure.

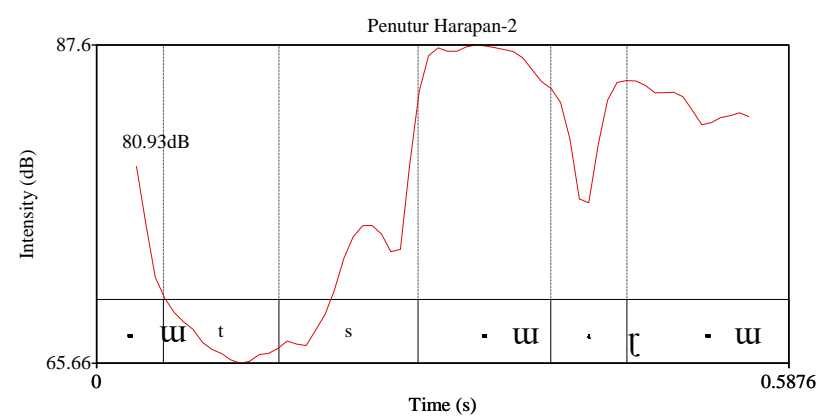

Figure 20. Intensity of Harapan-2 speaker for the word usıum

The devoicing of vowel [u] in the first syllable of the word [utsurm] uttered by the PH-2 speaker shows basic intensity $80.93 \mathrm{~dB}$, minimum intensity $65.66 \mathrm{~dB}$, and maximum intensity $87.6 \mathrm{~dB}$.

The devoicing intensity of vowel [i] in the first syllable of the word [ikimasm] by the Japanese native speaker is illustrated in the following figure.

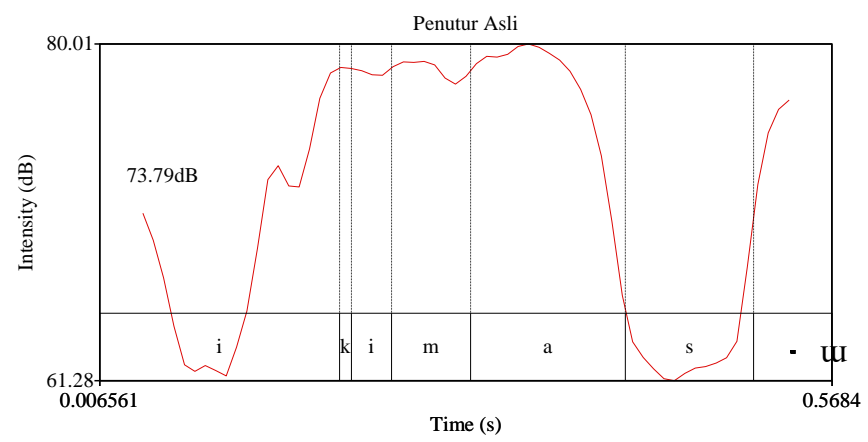

Figure 21. Intensity of a native speaker for the word ikimasu

The devoicing of vowel [i] in the first syllable of the word [ikimasw] uttered by the Japanese native speaker shows basic intensity $73.79 \mathrm{~dB}$, minimum intensity $61.28 \mathrm{~dB}$, and maximum intensity $80.01 \mathrm{~dB}$.

The devoicing intensity of vowel [i] in the first syllable of the word [ikimasu] uttered by the Japanese language learners from USU (PU-1) is demonstrated by the following figure. 


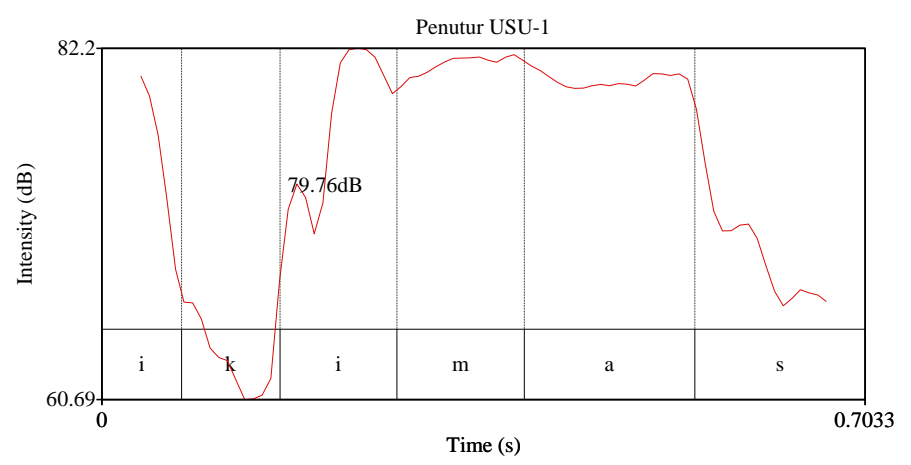

Figure 22. Intensity of USU-1 speaker for the word [ikimasw]

The devoicing of vowel [i] in the first syllable of the word ikimasu uttered by the PU-1 speaker shows basic intensity $79.761 \mathrm{~dB}$, minimum intensity $60.69 \mathrm{~dB}$, and maximum intensity $82.2 \mathrm{~dB}$.

The devoicing intensity of vowel [i] in the first syllable of the word [ikimasw] by the Japanese language learners from USU (PU-2) is showed by the following figure.

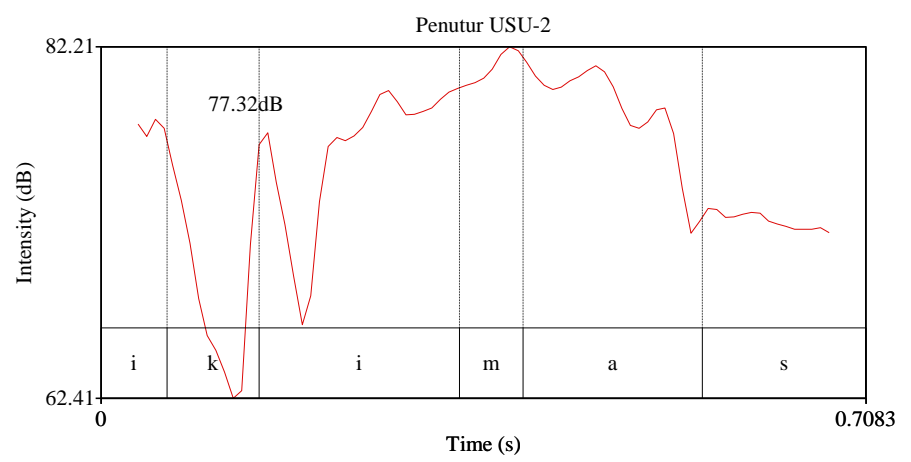

Figure 23. Intensity of USU-2 speaker for the word ikimasm

The devoicing of vowel [i] in the first syllable of the word [ikimasu] uttered by the PU-2 speaker shows basic intensity $77.32 \mathrm{~dB}$, minimum intensity $62.41 \mathrm{~dB}$, and maximum intensity $82.21 \mathrm{~dB}$.

The devoicing intensity of vowel [i] in the first syllable of the word [ikimasu] by the Japanese language learners from STBA Harapan (PH-1) is showed by the following figure.

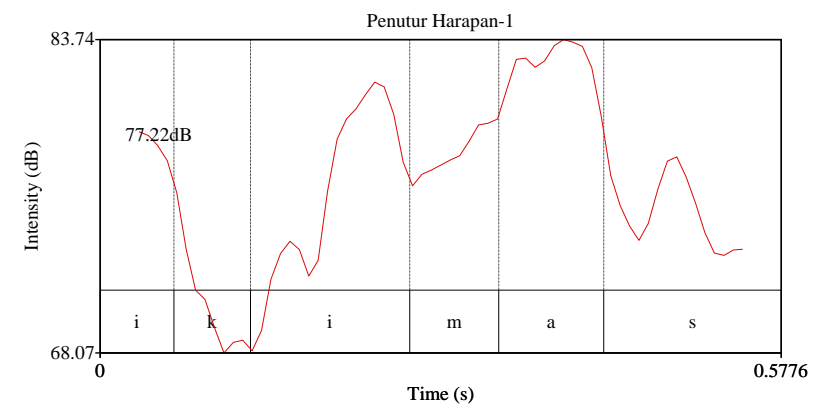

Figure 24. Intensity of Harapan-1 speaker for the word ikimasw 
The devoicing of vowel [i] in the first syllable of the word [ikimasu] uttered by the PH-1 speaker shows basic intensity $77.22 \mathrm{~dB}$, minimum intensity $68.07 \mathrm{~dB}$, and maximum intensity $83.74 \mathrm{~dB}$.

The devoicing intensity of vowel [i] in the first syllable of the word [ikimasu] by the Japanese language learners from STBA Harapan (PH-2) is showed by the following figure.

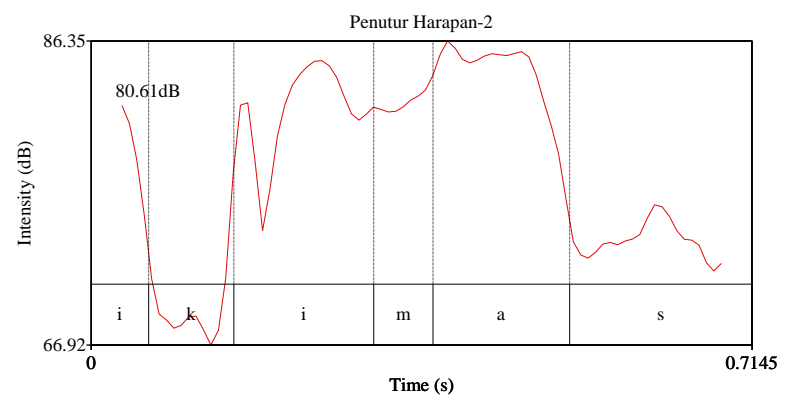

Figure 25. Intensity of Harapan-2 speaker for the word ikimasu

The devoicing of vowel [i] in the first syllable of the word [ikimasu] uttered by the PH-2 speaker shows basic intensity $80.61 \mathrm{~dB}$, minimum intensity $66.92 \mathrm{~dB}$, and maximum intensity $86.35 \mathrm{~dB}$.

The devoicing intensity of vowel [u] for the word [utfikefi] by the Japanese native speaker is as follows:

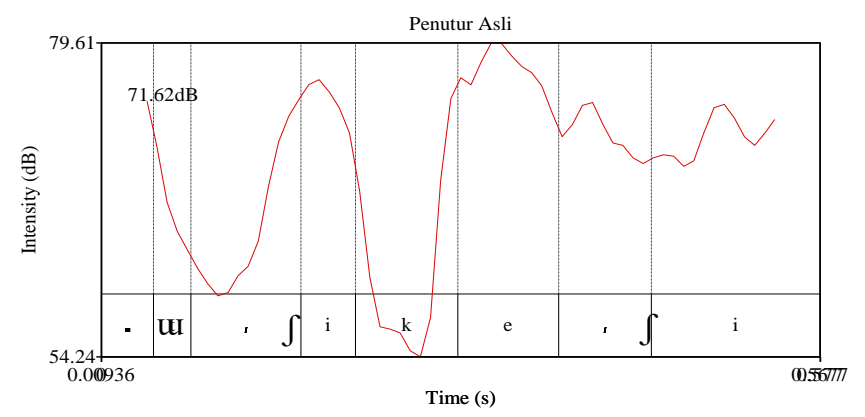

Figure 26. Intensity of a native speaker for the word utfikefi

The devoicing of vowel [u] in the first syllable of the word [utfikefi] uttered by the Japanese native speaker shows basic intensity $71.62 \mathrm{~dB}$, minimum intensity $54.24 \mathrm{~dB}$, and maximum intensity $79.61 \mathrm{~dB}$.

The devoicing intensity of vowel [u] in the first syllable of the word [utfikefi] uttered by the Japanese language learners from USU (PU-1) is as follows: 


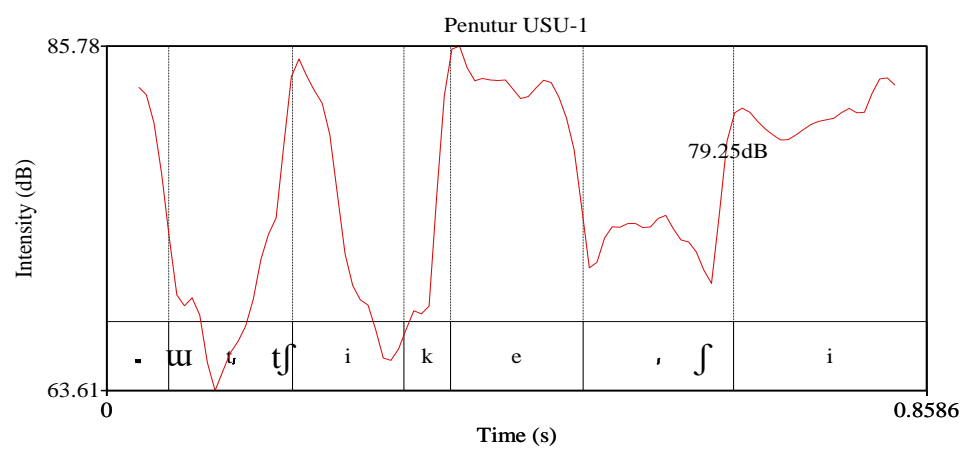

Figure 27. Intensity of USU-1 speaker for the word utfikefi

The devoicing of vowel [u] in the first syllable of the word [utfikefi] uttered by the PU-1 speaker shows basic intensity $79.25 \mathrm{~dB}$, minimum intensity $63.61 \mathrm{~dB}$, and maximum intensity $85.78 \mathrm{~dB}$.

The devoicing intensity of vowel [u] in the first syllable of the word [utfikefi] by the Japanese language learners from USU (PU-2) is as follows:

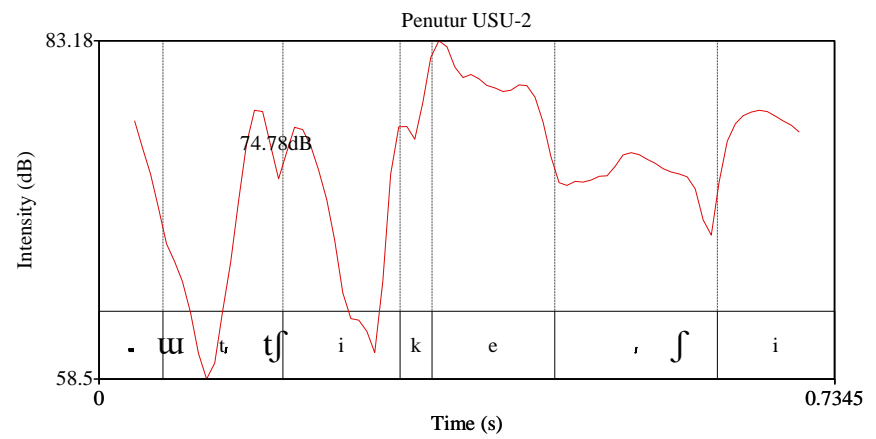

Figure 28. Intensity of USU-2 speaker for the word utfikefi

The devoicing of vowel [u] in the first syllable of the word [mtikefi] uttered by the PU-2 speaker shows basic intensity $74.78 \mathrm{~dB}$, minimum intensity $58.5 \mathrm{~dB}$, and maximum intensity $83.18 \mathrm{~dB}$.

The devoicing intensity of vowel [u] in the first syllable of the word [mtfikefi] by the Japanese language learners from STBA Harapan (PH-1) is as follows:

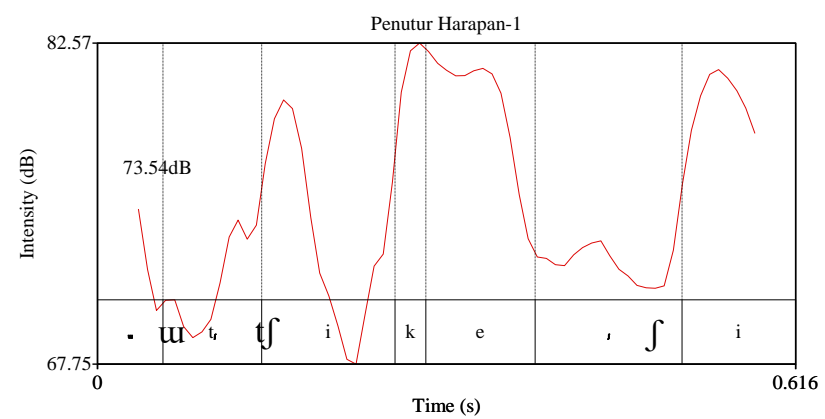

Figure 29. Intensity of Harapan-1 speaker for the word [utfikefi] 
The devoicing of vowel [u] in the first syllable of the word [utfikefi] uttered by the PH-1 speaker shows basic intensity $73.54 \mathrm{~dB}$, minimum intensity $67.75 \mathrm{~dB}$, and maximum intensity $82.57 \mathrm{~dB}$.

The devoicing intensity of vowel [u] in the first syllable of the word [utfikefi] by the Japanese language learners from STBA Harapan (PH-2) is as follows:

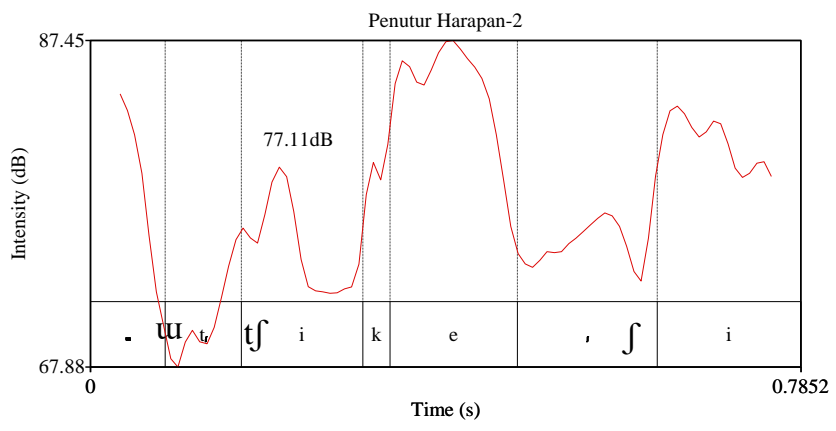

Figure 30. Intensity of Harapan-2 speaker for the word mtikefi

The devoicing of vowel [u] in the first syllable of the word [utfikefi] uttered by the PH-2 speaker shows basic intensity $77.11 \mathrm{~dB}$, minimum intensity $67.88 \mathrm{~dB}$, and maximum intensity $87.45 \mathrm{~dB}$.

Table 1. Intensity of vowels [i] and [u] in the first Syllable

\begin{tabular}{|c|c|c|c|c|c|}
\hline \multirow{2}{*}{$\begin{array}{l}\text { Word/inten } \\
\text { sity }\end{array}$} & \multicolumn{5}{|c|}{ Utterer } \\
\hline & PA & PU1 & PU2 & PH1 & $\mathrm{PH} 2$ \\
\hline \multicolumn{6}{|l|}{$[i k i]$} \\
\hline Bas.Inten & 69.26 & 74.59 & 77.47 & 75.31 & 74.10 \\
\hline Min Int & 52.04 & 58.27 & 59.94 & 67.98 & 67.07 \\
\hline Max Int & 78.39 & 84.13 & 82.35 & 82.12 & 83.35 \\
\hline \multicolumn{6}{|l|}{$[u / i]$} \\
\hline Bas.Inten & 73.86 & 78.45 & 77.84 & 78.58 & 76.96 \\
\hline Min Int & 71.65 & 73.65 & 68.53 & 74.21 & 74.03 \\
\hline Max Int & 76.42 & 83.02 & 81.87 & 83.03 & 86.58 \\
\hline \multicolumn{6}{|l|}{ [ikiru] } \\
\hline Bas.Inten & 74.36 & 81.91 & 78.66 & 78.68 & 82.71 \\
\hline Min Int & 55.11 & 60.10 & 62.06 & 68.05 & 66.12 \\
\hline Max Int & 79.38 & 84.30 & 81.44 & 76.94 & 84.32 \\
\hline \multicolumn{6}{|l|}{ [utswru] } \\
\hline Bas.Inten & 74.93 & 80.75 & 79.51 & 78.44 & 80.93 \\
\hline Min Int & 53.55 & 64.90 & 62.70 & 73.04 & 65.66 \\
\hline Max Int & 79.61 & 85.98 & 83.14 & 85.31 & 87.60 \\
\hline \multicolumn{6}{|l|}{ [ikimasw] } \\
\hline Bas.Inten & 73.79 & 79.76 & 77.32 & 77.22 & 80.61 \\
\hline Min Int & 61.28 & 60.69 & 62.41 & 68.07 & 66.92 \\
\hline Max Int & 80.01 & 82.20 & 82.21 & 83.74 & 86.35 \\
\hline \multicolumn{6}{|l|}{ [utfikefi] } \\
\hline Bas.Inten & 71.62 & 79.25 & 74.78 & 73.54 & 77.11 \\
\hline Min Int & 54.24 & 63.61 & 58.50 & 67.75 & 67.88 \\
\hline Max Int & 79.61 & 85.78 & 83.18 & 82.57 & 87.45 \\
\hline
\end{tabular}


Table 1 shows that, for the intensity of vowel [i] in the first syllable of the word [iki], the basic intensity which is closest to that of the Japanese native speaker as the speaker model is the PH-2 speaker with difference only $4.44 \mathrm{~dB}$ higher than the speaker model. As to the minimum intensity, the PU-1 speaker's intensity, $6.23 \mathrm{~dB}$ higher, is closest to the speaker model's intensity. The maximal intensity which is closest to that of the speaker model is the PH-1 speaker with difference of $3.33 \mathrm{~dB}$. Therefore, there is not any speaker who has the exactly same devoicing of vowels [i] for the word [iki] with the native speaker.

In addition, as to the intensity of vowel $[\mathrm{w}]$ in the first syllable of the word $[u / i]$, the basic intensity which is closest to that of the Japanese native speaker as the speaker model is the PH-2 speaker with difference only $3.1 \mathrm{~dB}$ higher than the speaker model. As for the minimum intensity, the PU-1 speaker's intensity, $2.00 \mathrm{~dB}$ higher is closest to the speaker model's intensity. The maximal intensity which is closest to that of the speaker model is the PU-2 speaker with difference of $5.45 \mathrm{~dB}$. Thus, there is not any speaker has the exactly similar devoicing of vowels $[\mathrm{w}]$ for the word $[u / i]$ to the native speaker.

The intensity of vowel [i] in the first syllable of the word [ikirm] shows that the PU-2 speaker has the closest basic intensity to that of the Japanese native speaker as the speaker model with difference only $4.3 \mathrm{~dB}$ higher than the speaker model. The PU-1 speaker's intensity, $4.99 \mathrm{~dB}$ higher, is closest to the speaker model's minimum intensity. The maximal intensity which is closest to that of the speaker model is the PU-1 speaker with difference of $2.06 \mathrm{~dB}$. Therefore, there is not any speaker with the exactly similar devoicing of vowels [i] for the word [ikiru] to the native speaker.

Furthermore, the intensity of vowel [u] in the first syllable of the word [utsuru] shows that the basic intensity which is closest to that of the Japanese native speaker as the speaker model is the PH-1 speaker with difference only $3.51 \mathrm{~dB}$ higher than the speaker model. The PU-2 speaker's minimum intensity, which is $9.15 \mathrm{~dB}$ higher, is closest to the speaker model's minimum intensity. The maximal intensity which is closest to that of the speaker model is the PU-2 speaker with difference of $3.53 \mathrm{~dB}$. As a result, there is no speaker has exactly same devoicing of vowels $[\mathrm{w}]$ for the word $[\mathrm{m} / \mathrm{i}]$ with the native speaker.

The intensity of vowel [i] in the first syllable of the word [ikimasu] shows that the closest basic intensity to that of the Japanese native speaker as the speaker model is the PH-1 speaker with difference only $3.43 \mathrm{~dB}$ higher. As to the minimum intensity, the PU-1 speaker's intensity, 0.59 $\mathrm{dB}$ higher, is closest to the speaker model's intensity. The maximal intensity which is closest to that of the speaker model is the PU-1 speaker with difference of $2.19 \mathrm{~dB}$. Therefore, there is not any speaker has the exactly same devoicing of vowels [i] for the word [ikimasu] with the native speaker. 
As to the intensity of vowel [u] in the first syllable of the word [utfikefi], the basic intensity which is closest to that of the Japanese native speaker as the speaker model is the PH-1 speaker with difference only $1.92 \mathrm{~dB}$ higher than the speaker model. As for the minimum intensity, the PU-1 speaker's intensity, $9.37 \mathrm{~dB}$ higher, is closest to the speaker model's intensity. The maximal intensity which is closest to that of the speaker model is the PH-1 speaker with difference of $2.96 \mathrm{~dB}$. Thus, there is not any speaker has the exactly similar devoicing of vowels $[u]$ for the word [utfikefi] to the native speaker.

\section{Conclusion}

According to the discussion of the research results gained from applying Praat program on the six target words uttered by four Japanese language leaners and a native speaker as the model in this research, the results were found disappointing. This occurred because through the measurement of the intensity of vowels [i] and [u] in the first syllables of the six target words, when uttered by the four Japanese language learners and compared to the speaker model who was a native speaker. It was found that there was none of them exactly similar to the speaker model.

Therefore, it can be concluded that the devoicing intensity of vowels [i] and [u] in the first syllable uttered by Japanese language learners from Japanese Study Program at the Faculty of Cultural Sciences USU and Japanese Department of STBA Harapan Medan was not maximal yet. It is thus necessary to increase the lecturers' performance in order to improve the learners' Japanese language skills. One of the techniques to find out the errors made by the learners in using Japanese is by applying Praat program as the measurement instrument.

\section{REFERENCES}

[1] K. Muneo, Dasar-Dasar Metodologi Pengajaran Bahasa Jepang. Dahidi dan Akahane, translator. Bandung: FPBS IKIP Bandung dengan The Japan Foundation. Real title: Kyojuho Nyumon, p. 14, 1988.

[2] T. Natsuko, An Introduction To Japanese Linguistics. USA: Blackwell Publishing, p. 2528, 1996.

[3] Tanaka, Shin'ichi \& K. Haruo, Introduction to Japanese Pronunciation. Theory and Practice. Tokyo: Kuroshio Shuppan, p. 8, 1999.

[4] L. Peter, A Course in Phonetics (3 Ed). New York: Harcourt, Brace and Jovanovich, p. 70-165, 1993.

[5] Sugiyono, Pedoman Penelitian Bahasa Lisan: Fonetik. Departemen Pendidikan Nasional, p. 68, 2003.

[6] L. Peter, Phonetic DataAnalysis. Oxford: Blackwell Publisshing, p. 90, 2003. 